\title{
Editorial: Symbioses Between Protists and Bacteria/Archaea
}

\author{
Alexei Yu. Kostygov ${ }^{1,2 * t}$, João M. P. Alves ${ }^{3 * t}$ and Vyacheslav Yurchenko ${ }^{1,4 * t}$ \\ ${ }^{1}$ Faculty of Science, Life Science Research Centre, University of Ostrava, Ostrava, Czechia, ${ }^{2}$ Zoological Institute of the \\ Russian Academy of Sciences, St. Petersburg, Russia, ${ }^{3}$ Department of Parasitology, University of São Paulo, São Paulo, \\ Brazil, ${ }^{4}$ Martsinovsky Institute of Medical Parasitology, Sechenov University, Moscow, Russia
}

Keywords: protists, prokaryotic symbionts, metabolism, ecology, genomics, holobiont concept

\section{Editorial on the Research Topic}

\author{
Symbioses Between Protists and Bacteria/Archaea
}

\section{OPEN ACCESS}

Edited by:

Robert Czajkowski,

University of Gdansk, Poland

Reviewed by:

Jörg Soppa,

Goethe Business School, Germany

Philippe M. Oger,

UMR5240 Microbiologie, Adaptation et Pathogenie (MAP), France

${ }^{*}$ Correspondence:

Alexei Yu. Kostygov

kostygov@gmail.com

João M. P. Alves

jotaj@usp.br

Vyacheslav Yurchenko

vyacheslav.yurchenko@osu.cz

tThese authors have contributed equally to this work

Specialty section: This article was submitted to

Microbial Symbioses, a section of the journal Frontiers in Microbiology

Received: 13 May 2021 Accepted: 06 July 2021

Published: 29 July 2021

Citation:

Kostygov AY, Alves JMP and Yurchenko V (2021) Editorial:

Symbioses Between Protists and Bacteria/Archaea.

Front. Microbiol. 12:709184.

doi: 10.3389/fmicb.2021.709184
Symbiosis is a regular long-term cohabitation of organisms of two (or more) species, of which at least one partner benefits. Such relationships can be classified as parasitism, commensalism, or mutualism, depending on whether they are harmful, neutral or beneficial to another partner (Douglas, 2010). The evolution of eukaryotes was always driven by various symbioses with prokaryotes. The very origin of this group about 1.5 billion years ago was associated with the acquisition by a proto-eukaryote of an $\alpha$-proteobacterial endosymbiont, which later became the mitochondrion. The rise of algae and, later, land plants, which significantly changed the whole biosphere, became possible owing to the establishment of endosymbiotic relationships with cyanobacteria, which turned into plastids (Keeling et al., 2015).

Symbiotic associations with prokaryotes were most intensively studied in plants and animals because of their practical importance, whereas much less attention has been paid to those in protists. Meanwhile, studying this phenomenon in unicellular eukaryotes is advantageous, since they represent simpler and at the same time more diverse models, allowing its deeper investigation. The studies presented in this Research Topic were focused on the diversity, stability, and specificity of symbiotic associations between protists and bacteria/archaea, as well as symbionts' genomics, metabolic contribution and their role in shaping the relationships of parasitic protists with animals.

Some protists may host entire consortia of microorganisms, as exemplified by the giant amoeba Pelomyxa palustris processing sapropel with the help of one archaeal and two bacterial endosymbionts (Gutiérrez et al., 2017), or the termite gut-inhabiting parabasalian Trichonympha spp., combining bacterial endo- and ectosymbionts in order to feed on wood particles (Stephens and Gage, 2020). These relationships may range from transient facultative associations, such as those between Acanthamoeba spp. and various bacteria (Guimaraes et al., 2016), to finely-tuned (as a result of a long-term coevolution) obligate systems observed in trypanosomatids of the subfamily Strigomonadinae (Alves et al., 2013; Silva et al., 2018).

For many symbiotic associations the exact nature of relationships between protists and their prokaryotic cohabitants is uncertain. However, there are examples of apparent mutualism, e.g., Pandoraea novymonadis in the trypanosomatid Novymonas esmeraldas (Kostygov et al., 2017) or Phycorickettsia trachydisci in the eustigmatophyte alga Trachydiscus minutus (Yurchenko et al., 2018) and parasitism e.g., Holospora spp. in Paramecium spp. (Fokin and Görtz, 2009).

Some symbioses are medically relevant, when a protist carries bacteria pathogenic to humans, e.g., Mycoplasma hominis in Trichomonas vaginalis (both obligately parasitic in genital tract) or Legionella pneumophila, Vibrio cholera, Listeria monocytogenes, Escherichia coli, etc. in facultatively parasitic acanthamoebae. Such associations were reviewed in this Research Topic by Henriquez et al., who demonstrated that the presence of bacterial symbionts may significantly 
aggravate the pathogenesis of infections by $T$. vaginalis and Acanthamoeba spp.

Hunter et al. analyzed the genomes and transcriptomes of the apicomplexan Cardiosporidium cionae and its yet unnamed bacterial endosymbiont of the family Rickettsiaceae. This parasite and the related mutualistic genus Nephromyces inhabit tunicates and represent the only Apicomplexa carrying symbiotic bacteria. The genomic analysis revealed that $C$. cionae obtains essential nutrients, including lysine and lipoic acid, from its endosymbiont. The authors propose that the metabolic contribution, provided by three endosymbionts of Nephromyces, allowed it to become mutualistic to its tunicate host, whereas the contribution of a single bacterium of Cardiosporidium is not sufficient for such a transition.

The work of Weiler et al. investigated resistance of Paramecium caudatum to the endonuclear parasitic bacterium Holospora undulata in different strains isolated in numerous countries across the world. Although the resistance varied significantly, the authors detected its positive correlation with genetic and geographic distances between the ciliate strains. For example, $P$. caudatum from Europe appeared to be more susceptible to the infection by European bacteria. This suggests that the farther away the populations of $P$. caudatum are from each other, the higher are the chances that their defense mechanisms differ and the strategy used by $H$. undulata would have to be changed.

Mironov and Sabaneyeva investigated another endosymbiotic association including Paramecium, but a different species, P. multimicronucleatum. Similarly to the case of Cardiosporidium cionae mentioned above, it hosts a bacterium of the family Rickettsiaceae, namely $\mathrm{Ca}$. Trichorickettsia mobilis. In contrast to the Paramecium-Holospora system, the relationship between the ciliate and its intranuclear symbiont is robust and the latter cannot be removed by any of the four antibiotics tested (ampicillin, streptomycin, chloramphenicol, tetracycline), each with a different mode of action. The antibiotics either did not kill any of the partners of this symbiotic association or, at high concentrations, caused the death of both. As the authors demonstrated, tetracycline, the drug most efficient against

\section{REFERENCES}

Alves, J. M., Klein, C. C., da Silva, F. M., Costa-Martins, A. G., Serrano, M. G., Buck, G. A., et al. (2013). Endosymbiosis in trypanosomatids: the genomic cooperation between bacterium and host in the synthesis of essential amino acids is heavily influenced by multiple horizontal gene transfers. BMC Evol. Biol. 13:190. doi: 10.1186/1471-2148-13-190

Douglas, A. E. (2010). The Symbiotic Habit. Princeton, N.J.: Princeton University Press.

Fokin, S. I., and Görtz, H.-D. (2009). "Diversity of Holospora bacteria in Paramecium and their characterization," in Endosymbionts in Paramecium, 1st Edn., ed M. Fujishima (Berlin, Heidelberg: Springer), 161-199.

Guimaraes, A. J., Gomes, K. X., Cortines, J. R., Peralta, J. M., and Peralta, R. H. (2016). Acanthamoeba spp. as a universal host for pathogenic microorganisms: one bridge from environment to host virulence. Microbiol. Res. 193, 30-38. doi: 10.1016/j.micres.2016.0 8.001 bacteria of the family Rickettsiaceae, is also toxic to the ciliates. This has also been previously shown for several other protist groups. Ampicillin and chloramphenicol caused the formation of dormant persisters out of active $\mathrm{Ca}$. Trichorickettsia mobilis cells, contributing to the stability of the system under study. Based on that, the authors proposed this symbiotic association as a model to elaborate the concept of the holobiont (an organism with its associated microbiota), originally introduced by Husnik et al. (2021).

The topic of symbiosis in such fascinating and diverse group as protists can hardly be exhausted and surely has many aspects still unclarified or completely unknown. As new lineages of protists are discovered every year, the vast amount of their diversity still remains to be explored. There is a rather limited number of endosymbiotic systems involving protists established as experimental models amenable to genetic modification. Such models would allow detailed investigation of the mechanisms underlying the complex relationships between the eukaryotic and prokaryotic partners. With the new cellular, molecular and genomic technologies and approaches applied to the study of symbiosis in protists, the pace of discovery in the field is sure to increase in ever accelerating rate. After the acceptance of this paper for publication, a relevant review on the topic has been published (Margulis, 1991). We address the readers to it for further information about the symbioses between protists and bacteria and/or archaea.

\section{AUTHOR CONTRIBUTIONS}

All authors listed have made a substantial, direct and intellectual contribution to the work, and approved it for publication.

\section{FUNDING}

The authors were supported by European Regional Development Funds (project Centre for Research of Pathogenicity and Virulence of Parasites CZ.02.1.01/16_019/0000759) to VY and AK and State Assignment AAAA-A19-119031390116-9 for ZIN RAS to AK.
Gutiérrez, G., Chistyakova, L. V., Villalobo, E., Kostygov, A. Y., and Frolov, A. O. (2017). Identification of Pelomyxa palustris endosymbionts. Protist 168, 408-424. doi: 10.1016/j.protis.2017.0 6.001

Husnik, F., Tashyreva, D., Boscaro, V., George, E. E., Lukeš, J., and Keeling, P. J. (2021). Bacterial and archaeal symbioses with protists. Curr. Biol. 31, R862-R877. doi: 10.1016/j.cub.2021. 05.049

Keeling, P. J., McCutcheon, J. P., and Doolittle, W. F. (2015). Symbiosis becoming permanent: survival of the luckiest. Proc. Natl. Acad. Sci. U.S.A. 112, 10101-10103. doi: 10.1073/pnas.151334 6112

Kostygov, A. Y., Butenko, A., Nenarokova, A., Tashyreva, D., Flegontov, P., Lukeš, J., et al. (2017). Genome of Ca. Pandoraea novymonadis, an endosymbiotic bacterium of the trypanosomatid Novymonas esmeraldas. Front. Microbiol. 8:1940. doi: 10.3389/fmicb.2017.0 1940 
Margulis, L. (1991). "Symbiogenesis and symbionticism," in Symbiosis as a Source of Evolutionary Innovation: Speciation and Morphogenesis, eds L. Margulis and R. Fester (Cambridge, MA: MIT Press), 1-14.

Silva, F. M., Kostygov, A. Y., Spodareva, V. V., Butenko, A., Tossou, R., Lukeš, J., et al. (2018). The reduced genome of Candidatus Kinetoplastibacterium sorsogonicusi, the endosymbiont of Kentomonas sorsogonicus (Trypanosomatidae): loss of the haem-synthesis pathway. Parasitology 145, 1287-1293. doi: 10.1017/S003118201800 046X

Stephens, M. E., and Gage, D. J. (2020). Single-cell amplicon sequencing reveals community structures and transmission trends of protist-associated bacteria in a termite host. PLOS ONE 15:e0233065. doi: 10.1371/journal.pone.023 3065

Yurchenko, T., Ševčiková, T., Pribyl, P., El Karkouri, K., Klimeš, V., Amaral, R., et al. (2018). A gene transfer event suggests a long-term partnership between eustigmatophyte algae and a novel lineage of endosymbiotic bacteria. ISME J. 12, 2163-2175. doi: 10.1038/s41396-018-0 $177-\mathrm{y}$
Conflict of Interest: The authors declare that the research was conducted in the absence of any commercial or financial relationships that could be construed as a potential conflict of interest.

Publisher's Note: All claims expressed in this article are solely those of the authors and do not necessarily represent those of their affiliated organizations, or those of the publisher, the editors and the reviewers. Any product that may be evaluated in this article, or claim that may be made by its manufacturer, is not guaranteed or endorsed by the publisher.

Copyright $\odot 2021$ Kostygov, Alves and Yurchenko. This is an open-access article distributed under the terms of the Creative Commons Attribution License (CC BY).

The use, distribution or reproduction in other forums is permitted, provided the original author(s) and the copyright owner(s) are credited and that the original publication in this journal is cited, in accordance with accepted academic practice. No use, distribution or reproduction is permitted which does not comply with these terms. 